Arteterapia. Papeles de arteterapia y educación para inclusión social ISSN-e 1988-8309

\title{
Supervisión en Arteterapia: perspectivas y modelos en intervención clínica y social
}

Cristina Ramos ${ }^{1}$, Ana Hernández ${ }^{2}$

Presentamos este monográfico con el objetivo de ampliar y actualizar la mirada en torno a la Supervisión en Arteterapia, la cual se convierte en una herramienta fundamental de nuestra práctica al igual que se da en otras disciplinas familiares como son las psicoterapias y las terapias expresivas.

La importancia que nos inspira esta materia, permite a los distintos autores, profundizar en los aspectos más significativos de la supervisión a través del análisis de los distintos modelos, la descripción de metodologías o el interés del seguimiento de ciertas intervenciones y el efecto de la supervisión en el desarrollo de las mismas.

Tras la publicación en 2013 por parte de la FEAPA, Federación de Asociaciones de Arteterapia de España, del título Reflexiones acerca de la supervisión en Arteterapia en la que participan varios autores y obras como Supervison of Art therapy en 2007, editado por Joe Schaverien y Caroline Case, A travellers guide to Art Therapy supervison 2011 de Mónica Carpendale, a nuestro modo de ver, sigue latente el deseo de profundizar en un aspecto tan compartido y relevante de nuestra profesión. Prueba de ellos es que las asociaciones de profesionales y estudiantes, observan la necesidad de investigar sobre la cuestión, organizando jornadas y seminarios en torno a la supervisión en Arteterapia, como es el caso de la asociación ANDART en abril de 2018.

Las formaciones más exigentes junto con los profesionales con mayor experiencia y trayectoria, consideran la supervisión estructurada y continuada como un eje fundamental para poder desarrollar la Arteterapia dentro de unos parámetros bien definidos y rigurosos. Por tanto se convierte en una necesidad cada vez más demandada por parte de los profesionales el garantizar el ejercicio de la misma de manera accesible y continuada, independientemente del ámbito de intervención en el que lleven a cabo su práctica, clínico, educativo o social.

La evolución y avance de nuestra profesión, conlleva el desarrollo de modelos de Supervisión propios del ámbito como son aquellos en los que se promueve el uso de la respuesta artística o de las obras post-sesión en la que los y las arteterapeutas,

1 Educadora Social Licenciada en Psicopedagogía y Máster en Arteterapia y Educación Artística para la Inclusión Social UCM, Arteterapeuta en Instituto Centta y en CET José Germain, Presidenta de la asociación AFIA, Foro Iberoamericano de Arteterapia.

E-mail: cristinaramosruiz@gmail.com

2 Dra. en Bellas Artes, Arteterapeuta, Terapeuta Ocupacional en Salud Mental (Agència Valenciana de Salut). Supervisora de Arteterapeutas. Codirectora Máster de Arteterapia de la Universitat Politècnica de València. Miembro fundador de MURART y de IDECART.

E-mail: arteterapia@upvnet.upv.es 
como Garía Reyna o Barbara J. Fish, utilizan el lenguaje artístico como vía de profundización y de análisis.

Por todo ello, hemos considerado que un monográfico sobre supervisión aportará conocimiento y riqueza a la comunidad investigadora, así como al conjunto de profesionales que conforman el grueso de los y las arteterapeutas.

El siguiente monográfico tiene por objetivos:

- Profundizar sobre distintos estilos de supervisión, metodologías y marcos teóricos.

- Conocer los resultados de distintas intervenciones que han sido guiadas en supervisión continua.

- Ensalzar el valor de la supervisión continua en los distintos ámbitos de intervención.

- Conocer distintos modelos de intervención: individual, grupal, artística, etc.

- Presentar miradas diversas de profesionales en torno a la supervisión en Arteterapia y sus requisitos.

La supervisión abre un lugar donde la reflexión se desarrolla, ayuda a arriesgar y a crear hipótesis, en un espacio de confianza, donde aprenden todos los implicados. Se dan las preguntas o dudas de manera libre, o ayuda a conocerse y a confiar. A reconocer deseos, frustraciones y límites, a ver las proyecciones, es decir hacer más consciente la contratransferencia. En definitiva, ayuda a confirmar intuiciones y pasar a la acción. 